\title{
Inserción global, desarticulación y competitividad en el sector electromecánico de México: un análisis estructural
}

\author{
Raúl Vázquez López
} en el período 1994-2008, diferenciando del resto las actividades globalizadas. Al estimar la productividad laboral de 52 clases industriales, se halla un crecimiento de la heterogeneidad estructural sobre todo en el lapso 1994-2001, concomitante de la progresiva concentración de las mejoras técnicas y organizativas en un número reducido de empresas filiales de transnacionales del ensamblaje automotriz. Otro resultado obtenido mediante la utilización de una técnica diferencial-estructural es la ausencia de un cambio estructural significativo. Finalmente, la aplicación de una extensión de la metodología para evaluar la competitividad —elaborada por la Comisión Económica para América Latina y el Caribe (CEPAL) - a una segunda base de datos en que se reclasifican 1.345 productos del comercio exterior, permite contrastar estas transformaciones con el dinamismo de las redes globales de producción en que se insertan las empresas líderes del sector en México.

PALABRAS CLAVE

CLASIFICACIÓN JEL
Industrias mecánicas y eléctricas, organización industrial, especialización de la producción, productividad, competitividad, evaluación, México

F68, L16, L62

Raúl Vázquez López es investigador titular "B” del Instituto de Investigaciones Económicas de la Universidad Nacional Autónoma de México (unam), Unidad de Economía Industrial, México.rvazquez@unam.mx 


\section{I}

\section{Introducción}

A partir de los años ochenta se implementa en México y algunos países de América Latina una estrategia de desarrollo económico basada en la apertura comercial y la desregulación de la economía. Las medidas establecidas —inspiradas en una visión ortodoxa que estima que el mercado posee capacidad autónoma para asignar los recursos de forma eficiente- tienen entre otros objetivos fomentar un cambio estructural en el sistema productivo por medio de la inserción de las actividades líderes del modelo en eslabonamientos globales de valor. En el contexto de una sofisticada división internacional del trabajo, la estrategia sustentada en la especialización productiva presupone que el libre funcionamiento de los mercados, con el apoyo de las medidas establecidas, permite la generación de empleo así como la reubicación de factores en dirección de los usos más productivos.

Tres décadas más tarde, los resultados obtenidos han puesto en tela de juicio la validez de esta argumentación. En el caso de México, la política pública se ha ceñido de manera ejemplar a los lineamientos ortodoxos. La liberalización comercial y la desregulación de la economía siguieron un ritmo acelerado, mientras que la actividad maquiladora llegó a registrar un auge sin precedentes. Obteniendo provecho de las ventajas otorgadas por la cercanía geográfica con el mercado de los Estados Unidos de América y por la firma del Tratado de Libre Comercio de América del Norte (TLCAN), grandes empresas transnacionales han invertido en el país y las exportaciones de productos ensamblados en México han crecido a tasas superiores a las del comercio mundial. No obstante, la competitividad externa de las industrias líderes del modelo no ha sido capaz de contrarrestar el proceso de desindustrialización en las ramas no globalizadas de la economía, víctimas de la competencia en el mercado interno por parte de unas importaciones beneficiadas por las medidas establecidas.

Desde la tradición teórica del pensamiento estructural latinoamericano, los efectos de arrastre de las industrias más eficientes en términos de la transferencia de capacidades tecnológicas, formas de organización y demanda de insumos, son fundamentales en la consecución de una transformación significativa del sector productivo que sustente no solo el crecimiento económico, sino también el desarrollo en un sentido más amplio. En 1970, al considerar la experiencia histórica de los países desarrollados, Aníbal Pinto planteó como un objetivo central en el desenvolvimiento de las industrias modernas, definidas como aquellas de mayor nivel de productividad, que estas transmitieran su progreso al resto de la economía, ayudando a "levantar" las poblaciones, áreas o sectores rezagados (Pinto, 1970, pág. 97). Al respecto, esta misma experiencia histórica muestra que la implementación de un cambio estructural basado en el desarrollo de complementariedades entre las diferentes actividades requiere de la participación de un complejo entramado institucional ${ }^{1}$.

De acuerdo con este orden de ideas, el objetivo del presente artículo es analizar la evolución estructural del sector electromecánico mexicano, líder del patrón exportador manufacturero del país, destacando el dualismo existente entre las actividades globalizadas y las no globalizadas. Con este fin, se construyeron dos bases de datos para el período 1994-2008 al mayor nivel de desagregación posible, una de ellas en referencia a los niveles de productividad laboral de 52 clases de actividad del sector, y una segunda - fruto de la reclasificación inexistente a la fecha de 1.345 productos bajo la Clasificación del Sistema Arancelario 1992 (SA92) de comercio exterior en términos de la Clasificación Mexicana de Actividades y Productos (CMAP) — relativa a las exportaciones e importaciones de las diferentes actividades sectoriales (véase el anexo). Los resultados de diferentes ejercicios estadísticos realizados a partir de estas fuentes de información representan el cuerpo del trabajo.

En la primera parte de la sección II, de índole teórico, se debate el papel de la política pública en la inserción de las industrias líderes de la manufactura mexicana en redes globales de producción, y en la segunda parte se documenta la evolución en un sentido concentrador de las participaciones de las distintas actividades del sector electromecánico en la producción y el empleo del sector. En la sección III se aborda la transformación heterogénea de los niveles desagregados de la productividad laboral, mientras que en la cuarta, mediante la utilización de

\footnotetext{
1 De hecho, José Antonio Ocampo, ex Secretario Ejecutivo de la CEPAL, define el concepto de complementariedades de forma extensa, haciendo referencia no solo al papel de los encadenamientos hacia atrás y hacia delante destacados por Hirschman, sino también al papel de las instituciones públicas, privadas o mixtas creadas con el fin de reducir los costos de información (Ocampo, 2005).
} 
una técnica genérica de tipo diferencial estructural, se distinguen los principales determinantes de los cambios observados. Finalmente, tras evaluar en la sección V el desempeño competitivo externo en términos dinámicos del sector y sus limitaciones, en la sección VI se presentan las principales conclusiones.

\section{II}

\section{Política pública en México y redes globales de producción}

Arndt y Kierzkowski (2001) vinculan el fenómeno de la fragmentación internacional de la producción al surgimiento de actividades de ensamblaje o maquila en países rezagados, y definen este fenómeno como la división en uno o más componentes de procesos productivos previamente integrados, cuya manufactura se desplaza geográficamente dando lugar al intercambio intraindustria e intraproducto. Por su parte, Yamashita (2008) puntualiza que esta división transfronteriza del proceso productivo redunda en la reubicación de segmentos de actividad intensivos en mano de obra de baja calificación en dirección de países en desarrollo $\mathrm{y}$, por el contrario, en la retención en países avanzados de tareas de elevado contenido en conocimiento o relacionadas con tecnologías sofisticadas.

De lo anterior se deduce una forma de organización global altamente jerarquizada y rígida, cuya distribución de los beneficios es desigual y conlleva una redoblada especialización de las economías nacionales. De esta manera, los segmentos productivos intensivos en capital estarían fuera del "cono de especialización" de países en desarrollo con abundancia en mano de obra, por lo que las tareas de mayor contenido en tecnología y conocimiento no solo no se desplazan en dirección de estos países, sino que además desaparecen de ellos cuando existen previamente (Deardoff, 1979). Al contrastar la teoría con el caso del sector manufacturero mexicano, Puyana y Romero señalan que este fenómeno explicaría la disminución del contenido nacional de algunas actividades, como del sector automotriz, por ejemplo, que tuvo lugar luego de la apertura de la economía mexicana desde la crisis de la deuda (Puyana y Romero, 2006, pág. 72).

Al introducir elementos de economía política geográfica al análisis de las redes globales de producción, MacKinnon (2012) encuentra que el papel de las instituciones ha sido asegurar el acoplamiento estratégico ${ }^{2}$

2 Yeung (2009, pág. 213) define el acoplamiento estratégico como el proceso dinámico a través del cual actores en ciudades, regiones entre las potencialidades existentes localmente y las necesidades planteadas por las firmas conductoras de estas redes internacionales. Coe y otros (2004) mencionan, a su vez, el papel de estas instituciones en moldear dichas capacidades locales con el fin de complementar las estrategias perfiladas por actores transnacionales situados en el seno de estas redes globales de producción. En suma, las empresas transnacionales condensan un poder sistémico que ejercen en función de sus necesidades derivadas de la maximización de sus beneficios, de manera de transformar los marcos regulatorios nacionales y subnacionales, así como —en definitiva- las estructuras productivas que subordinan (Dawley, 2011). En algunas reflexiones se llega incluso a tipificar de "captura corporativa" la posibilidad que tienen las empresas transnacionales de poner a su servicio las capacidades institucionales en detrimento de los intereses de empresas y trabajadores nacionales (Phelps, 2008).

\section{Inserción de las industrias líderes de la manufactura mexicana en redes globales de producción}

Lo señalado anteriormente es sobre todo relevante en cuanto al papel de las instituciones públicas en países en desarrollo especializados en tareas de ensamblaje manufacturero, como es el caso de México. El fomento de la importación de componentes, bienes intermedios e insumos libres de impuestos, así como la aceptación de pagar un gravamen al valor agregado del producto al ser reexportado al país de origen por parte de las autoridades nacionales, han tenido como fin apuntalar las estrategias de organización de estas redes globales de producción en desmedro de los encadenamientos productivos y el nivel de ingresos locales (Yeats, 2001).

o en ambas coordinan, median y arbitran intereses estratégicos entre actores locales y sus contrapartes en la economía global. 
En realidad, en la mayoría de los casos, las medidas públicas para atraer inversión extranjera y actividades maquiladoras por parte de los países en desarrollo han desincentivado el contenido nacional en el proceso de fabricación, y son el resultado en última instancia de las necesidades creadas por las presiones competitivas experimentadas a nivel de las casas matrices de las grandes empresas transnacionales en países avanzados (Arndt, 2001).

En el caso de México, Puyana y Romero (2006) documentan una "bonanza" de la maquila originada en los estímulos fiscales otorgados por los Gobiernos de México y de los Estados Unidos de América tendientes a reducir los costos productivos, ampliar la rentabilidad y estimular inversiones en la actividad maquiladora, con el consiguiente traslado de factores productivos en dirección de dicha actividad. Bajo este esquema, la escasa incorporación de valor agregado nacional en los bienes exportados se explica por el efecto combinado de los estímulos a la importación libre de impuestos de componentes, el cobro en los Estados Unidos de América del gravamen sobre el valor añadido mexicano, la lógica global de la fragmentación de los procesos productivos limitante del desarrollo de actividades intensivas en capital y conocimiento, y la revaluación cambiaria que eleva el costo de los insumos domésticos.

En este sentido, la política pública ha tenido un sesgo marcadamente favorable a los intereses de los agentes transnacionales a partir del establecimiento de la estrategia económica de corte neoliberal, basada en la desregulación financiera y la apertura comercial. En 1996, el Programa de Política Industrial y Desregulación Económica se integró al Programa de Comercio Exterior y Promoción de Exportaciones en el entendido de que, en el contexto de la globalización, las medidas de promoción no deben separarse de las relacionadas con los intercambios internacionales (Hernández, 2000). El programa resultante, marco de referencia de la política industrial nacional, favoreció entonces al sector exportador por sobre el fabricante de bienes no "transables", teniendo de hecho por objetivo central fomentar la competitividad del aparato productivo y su integración en redes globales de producción.

Muestra fehaciente de la responsabilidad de las autoridades en la transformación experimentada por la manufactura fue la implementación de programas específicos de fomento en torno de dos líneas principales de acción: impulsar las exportaciones (ECEX y ALTEX ${ }^{3}$ )

\footnotetext{
${ }^{3}$ Programa Empresas de Comercio Exterior (ECEX) y Programa de Empresas Altamente Exportadoras (ALTEX).
}

y desarrollar la actividad maquiladora (PITEX, INMEX y DRAWBACK $)^{4}$. En lo que atañe a estos últimos programas, destacan las disposiciones referentes a la exención del pago de impuestos (general de importación, al valor agregado, y así como, en su caso, de cuotas compensatorias) a las importaciones temporales de bienes intermedios e insumos utilizados en los procesos de elaboración, transformación o reparación de mercancías de exportación. De esta manera, el patrón de especialización industrial delineado por las medidas aplicadas favoreció la inclusión en forma subordinada de la planta productiva nacional en sectores globalizados controlados por la "gobernanza" de redes globales de producción (Vázquez, 2012).

En el sector automotriz, pilar en la estrategia de crecimiento, el Estado desmanteló progresivamente una normativa que había sido hasta entonces exitosa en cuanto a su capacidad de incentivar las exportaciones y desarrollar la industria nacional de piezas para vehículos. Con la supresión del Decreto Automotriz se eliminaron: el límite máximo de capital extranjero en empresas de repuestos para vehículos (49\% originalmente), el requisito de valor agregado nacional en la producción de ensambladoras (ubicado en el 60\% hasta antes de 1998), y la obligación de exportar un valor mínimo por cada dólar de importación (antes del TLCAN, se exigía 1,75 dólares por cada dólar de importación) (Hernández, 2000). La desregulación significó entonces una reducción del número de tareas realizadas, siguiendo una trayectoria determinada por las necesidades productivas del sistema global integrado, consistente en una mayor especialización en los segmentos finales de fabricación relacionados con el ensamblaje.

\section{Concentración y desarticulación en el sector electromecánico mexicano}

En el caso del sector electromecánico mexicano, el "acoplamiento" estratégico entre la estructura de fabricación y las necesidades de las redes globales de producción, perfiladas por casas matrices de empresas transnacionales, se ha hecho sobre todo patente - a raíz de la apertura comercial — en la creciente separación que existe entre las características de las industrias dedicadas a atender el mercado interno y las de aquellas insertas en eslabonamientos internacionales cuyo fin es la exportación. Con el objetivo de tener un primer acercamiento

\footnotetext{
4 Programa de Importación Temporal para Producir Artículos de Exportación (PITEX); Programa para la Industria Manufacturera, Maquiladora y de Servicios de Exportación (IMMEX) y Programa de Devolución de Impuestos de Importación a los Exportadores (DRAWBACK).
} 
diferenciado a la evolución del sector, se construyó una base de datos en que se estiman principalmente los niveles de productividad laboral separando las clases censadas en dos grupos (véase el anexo). En un primer conjunto se consideran las actividades relacionadas con las industrias automotrices y las referentes al subsector eléctrico-electrónico y fabricante de aparatos de uso doméstico y de oficina, que en adelante se identifica como grupo "globalizado", mientras que en un segundo conglomerado se aglutinan el resto de las actividades en el grupo llamado "no globalizado".

A nivel general, respecto del período de estudio (1994-2008) los datos muestran un estancamiento de las participaciones de los dos grupos considerados en el total del sector, tanto en términos del valor de la producción como de las horas-hombre trabajadas. Lo anterior apuntaría en dirección de la ausencia de un cambio estructural relevante, que incrementara el peso de las actividades insertas en eslabonamientos internacionales en el aparato de fabricación a raíz de la apertura comercial. No obstante, el análisis a un nivel más desagregado cuestiona dicha aseveración considerando que una sola actividad, "Fabricación y ensamble de automóviles y camiones" (clase 384110), la de mayor inserción global, incrementó su participación en el valor de la producción del 40,8\% en 1994 al 50,4\% en 2008, explicando en este último año la mitad de la generación total del sector y compensando con creces y significativamente la caída en la participación de su principal proveedora de insumos, la "Fabricación de motores y sus partes para automóviles y camiones" (clase 384122): de un 10,6\% en 1994 a un 6,6\% en 2008 (véase el cuadro 1).

CUADRO 1

Participación de los grupos de industrias
en la producción bruta total del sector e
índices de Herfindahl-Hirschman (IHHn),
1994 y 2008
(En porcentajes)

\begin{tabular}{lcc}
\hline Grupos & 1994 & 2008 \\
\hline Grupo globalizado & 80,1 & 81,8 \\
$\quad$ Clase de actividad 384110 & 40,8 & 50,4 \\
$\quad$ Clase de actividad 384122 & 10,6 & 6,6 \\
Grupo no globalizado & 19,9 & 18,3 \\
Total del sector & 100 & 100 \\
IHHn grupo globalizado & 41,3 & 52,9 \\
IHHn grupo no globalizado & 7,5 & 12,1 \\
IHHn total del sector & 34,1 & 43,8 \\
\hline
\end{tabular}

Fuente: elaboración propia sobre la base de datos del Instituto Nacional de Estadística y Geografía (INEGI), "Encuesta Industrial Mensual (EIM). Clasificación Mexicana de Actividades y Productos (CMAP), 205 clases de actividad económica”, 2013.
Las tendencias diametralmente opuestas experimentadas por las dos clases principales del sector e integradas en la misma rama y cadena de valor, reflejan la sustitución de proveedores locales de repuestos para vehículos por importaciones y, en consecuencia, la ruptura de los eslabonamientos productivos domésticos encabezados por industrias líderes insertas en redes globales de producción. Al respecto, en el contexto de la globalización del sector automotriz, Álvarez señala que "las empresas locales han dejado de ser proveedoras de las ensambladoras para dejar su lugar a las nuevas empresas extranjeras o dedicarse a importar y distribuir autopartes" (Álvarez, 2002, pág. 46). Esta hipótesis se ve confirmada comparando los resultados obtenidos al calcular los coeficientes de articulación e integración de los grupos globalizado y no globalizado, dado que mientras el primer indicador es inferior en $16,9 \%$, para el grupo globalizado, el segundo lo es en $11 \%$ (véase el cuadro 2$)^{5}$.

CUADRO 2

\section{Coeficientes de articulación e integración de los grupos de industrias, $2003^{a}$ (En porcentajes)}

\begin{tabular}{lcc}
\hline Grupos & $\begin{array}{c}\text { Coeficiente de } \\
\text { articulación }\end{array}$ & $\begin{array}{c}\text { Coeficiente de } \\
\text { integración }\end{array}$ \\
\hline Grupo globalizado & 44,6 & 56,7 \\
Grupo no globalizado & 61,5 & 67,8 \\
Total del sector & 46,6 & 58,5 \\
\hline
\end{tabular}

Fuente: elaboración propia sobre la base de datos del Instituto Nacional de Estadística y Geografía (INEGI), "Encuesta Industrial Anual. Clasificación Mexicana de Actividades y Productos (CMAP), 205 clases de actividad económica”, 2013.

a Los datos fueron calculados para el año 2003 por ser el último año para el que existe la información necesaria bajo la clasificación del CMAP.

b Coeficiente de articulación: materias primas y auxiliares nacionales consumidas/materias primas y auxiliares consumidas totales.

c Coeficiente de integración: (valor agregado + materias primas y auxiliares nacionales consumidas)/producción bruta total.

\footnotetext{
5 Tras revisar la información disponible en las distintas fuentes estadísticas, la definición de coeficiente de articulación empleada en este estudio corresponde al valor del consumo en materias primas y auxiliares nacionales como porcentaje del valor total consumido en dichos insumos. Por su parte, el coeficiente de integración se calculó como la parte de la suma del valor agregado y el valor de las materias primas y auxiliares nacionales consumidas en la producción bruta total respecto de cada una de las 53 clases de actividad del sector y para los grupos considerados. La fuente de información utilizada en este caso fue la Encuesta Industrial Anual, 205 clases de actividad (CMAP) del INEGI (2013b).
} 
Al respecto, el proceso de desarticulación de los eslabonamientos locales de valor en el sector es concomitante de una progresiva concentración de la producción, principalmente en una sola actividad controlada por filiales de grandes empresas transnacionales extranjeras (el ensamblaje intensivo en trabajo de automóviles y camiones) ${ }^{6}$. Así lo corrobora el cálculo del índice Herfindahl-Hirschman normalizado (IHHn) ${ }^{7}$, siendo que el indicador aumenta en todos los casos, pero en particular de forma considerable en el grupo globalizado, pasando del 41,3\% en 1994 al 52,9\% en 2008 (véase el cuadro 1). Existe entonces evidencia de una marcada correlación entre un proceso de apertura comercial —liderado por una política pública destinada a integrar el sistema productivo nacional a las redes globales de producción - y una tendencia a la especialización productiva que concentra en su seno la actividad en un número reducido de industrias y de empresas.

Cabe igualmente subrayar que debido al mayor nivel tecnológico de los procesos de fabricación en las clases globalizadas — por ejemplo, el sector automotriz-, tanto

\footnotetext{
${ }^{6}$ En 2008, la producción automotriz en México alcanzó a 2.180.294 de unidades, de las cuales el 76,4\% fueron destinadas al mercado internacional. En el caso de los automóviles, la fabricación ascendió en ese año a 1.387.913 unidades, de las cuales el 79,5\% fueron exportadas, $32,4 \%$ fueron producidas por la armadora alemana Volkswagen, $28,3 \%$ por la japonesa Nissan y $19,7 \%$ y $14,8 \%$ por las estadounidenses Ford y General Motors, respectivamente (INEGI, 2010).

7 El Índice Herfindahl-Hirschman normalizado se calculó para los valores de la producción y para las horas-hombre trabajadas de las 23 clases de actividad del grupo globalizado y para las 30 clases del grupo no globalizado por separado, así como para el conjunto de las 53 clases del sector siguiendo la fórmula
}

$$
\text { IHHn }=\frac{\left[\sqrt{\sum_{i=1}^{n} P_{i}^{2}}-\sqrt{\frac{1}{n}}\right]}{1-\sqrt{\frac{1}{n}}} \times 100
$$

donde: $P_{i}=X_{i} / X_{t}$ indica la participación de la clase $i$ en el valor total de la producción o de las horas-hombre trabajadas del conjunto considerado (fórmula normalizada sobre la base de Durán y Álvarez, 2008). el aumento de la participación de estas clases en el total sectorial, como su grado de concentración, son menores en términos de las horas-hombre trabajadas. Al comparar 2008 con 1994, el incremento de la parte correspondiente al grupo globalizado en el total del tiempo trabajado del sector es de solo un 2,2\%, mientras que el índice de concentración del grupo refleja un acrecentamiento residual de un 1,6\% (véase el cuadro 3). En consecuencia, un elemento que explicaría la falta de arrastre de las exportaciones en el crecimiento económico y el empleo es la incapacidad de estas empresas globalizadas para generar puestos de trabajo acordes con su importancia en la estructura productiva, lo que contradice el argumento teórico ortodoxo en lo relativo a la capacidad de la liberalización y el mercado para reubicar por sí solos el factor trabajo en dirección de usos más rentables. En este orden de ideas, dicho rasgo implicaría la imposibilidad de estas empresas de dinamizar un cambio estructural significativo, hipótesis que se evaluará en las secciones siguientes a través del análisis de las tendencias de los niveles de productividad laboral y de sus determinantes.

CUADRO 3

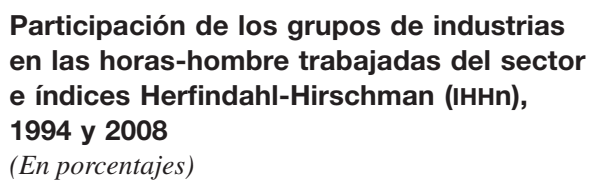

Participación de los grupos de industrias en las horas-hombre trabajadas del sector e índices Herfindahl-Hirschman (IHHn), 1994 y 2008

(En porcentajes)

\begin{tabular}{lrc}
\hline Grupos & 1994 & 2008 \\
\hline Grupo globalizado & 60,2 & 62,4 \\
$\quad$ Clase de actividad 384110 & 12,5 & 13,2 \\
Clase de actividad 384122 & 8,3 & 8,0 \\
Grupo no globalizado & 39,8 & 37,6 \\
Total del sector & 100 & 100 \\
IHHn grupo globalizado & 12,2 & 13,8 \\
IHHn grupo no globalizado & 5,6 & 6,7 \\
IHHn total del sector & 7,8 & 9,3
\end{tabular}

Fuente: elaboración propia sobre la base de datos del Instituto Nacional de Estadística y Geografía (INEGI), "Encuesta Industrial Mensual (EIM). Clasificación Mexicana de Actividades y Productos (CMAP), 205 clases de actividad económica”, 2013. 


\section{III}

\section{Evolución de la productividad laboral y heterogeneidad estructural}

En términos generales, las estimaciones realizadas a partir de la base de datos elaborada muestran una tasa de crecimiento de la productividad laboral a lo largo del período considerado (1994-2008) muy similar en los dos grupos de industrias (grupo globalizado y no globalizado), y en línea con la evolución del indicador tanto respecto del total del sector como de la manufactura en su conjunto (véase el cuadro 4). En el caso del grupo globalizado, 7 de las 23 clases registran una disminución en su nivel de productividad laboral al comparar 2008 con 1994, destacándose las clases "Fabricación, ensamble y reparación de equipos y aparatos para comunicación, transmisión y señalización” (383201) y "Fabricación y ensamble de radios, televisores y reproductores de sonido" (383204), sustantivas en la actividad exportadora de una industria electrónica nacional muy dependiente del funcionamiento de redes globales de producción. A pesar del éxito competitivo de estas actividades, cuyas ventas al extranjero alcanzaron en 2008 a 14.407 y 24.999 millones de dólares, respectivamente, es decir, en conjunto al 23,2\% de las exportaciones totales del sector ${ }^{8}$, su productividad laboral decreció considerablemente a tasas de 32,5\% y 47,3\% entre 1994 y 2008 (véase el cuadro 4). En consecuencia, cabe notar que el grupo globalizado de forma agregada no ostente un desempeño visiblemente superior en comparación con el grupo no globalizado, así como el indicio de una competitividad "espuria" no sustentada en mejoras tecnológicas y organizativas en algunas actividades marcadamente exportadoras.

En cuanto al ensamble de automóviles y camiones (clase 384110), la clase concentradora de la actividad del sector registra tanto el mayor nivel de productividad laboral de la muestra en 2008, como un aumento en dicho indicador muy superior a la media en el lapso 1994-2008. Por el contrario, la productividad laboral de su principal proveedora de insumos, la "Fabricación de motores y sus partes para automóviles y camiones" (clase 384122), representa solo el 21,4\% del nivel de la

8 En el caso de la clase 383201, sus exportaciones corresponden a la combinación de las siguientes categorías del SA92: $8517+8521+8525+8526+8530+8531-851790-853090-853190$. En cuanto a la clase 383204 , la identidad referida es $8518+8519+8520+8527+8528-$ 851850 (véase el anexo).

\begin{tabular}{lrrr} 
CUADRO 4 & \multicolumn{3}{c}{$\begin{array}{l}\text { Evolución de la productividad laboral por } \\
\text { grupos de industrias, 1994 y 2008 } \\
\text { (En pesos mexicanos de diciembre de 2003 } \\
\text { y porcentajes) }\end{array}$} \\
$\begin{array}{lrrr}\text { Grupos } \\
\text { Grupo globalizado }\end{array}$ & 1994 & 2008 & $\begin{array}{c}\text { Tasa de } \\
\text { crecimiento }\end{array}$ \\
\hline Clase de actividad 384110 & 1697,7 & 2892,4 & 43,1 \\
Clase de actividad 384122 & 664,0 & 619,4 & $-6,7$ \\
$\quad$ Clase de actividad 383201 & 744,7 & 502,5 & $-32,5$ \\
$\quad$ Clase de actividad 383204 & 699,3 & 368,5 & $-47,3$ \\
Grupo no globalizado & 259,1 & 366,1 & 41,3 \\
Total del sector & 519,4 & 755,3 & 45,4 \\
Total de la manufactura & 446,1 & 625,0 & 40,1 \\
\hline
\end{tabular}

Fuente: elaboración propia sobre la base de datos del Instituto Nacional de Estadística y Geografía (INEGI), "Encuesta Industrial Mensual (EIM). Clasificación Mexicana de Actividades y Productos (CMAP), 205 clases de actividad económica”, 2013.

industria terminal y experimenta además un retroceso en el período estudiado (véase el cuadro 4). $\mathrm{Al}$ respecto, el análisis del conjunto de las estimaciones realizadas apunta en dirección de la ampliación de las brechas en términos de eficiencia tanto entre actividades líderes y rezagadas del sector, profundización que también se aprecia al interior de las industrias insertas en redes globales de producción, especialmente entre aquellas agrupadas en las clases proveedoras de insumos y las de ensamblaje situadas en las últimas fases de la cadena de valor.

Considerando que, desde la perspectiva teórica adoptada, un proceso de homogeneización estructural es prerrequisito necesario para avanzar a formas más maduras de industrialización (Furtado, 1961; Pinto, 1965 y 1970), la ampliación de las brechas productivas en el interior de las industrias líderes del patrón de especialización exportador traduce una involución de la estructura de fabricación. Un primer acercamiento al tema de la heterogeneidad estructural en el sector metalmecánico mexicano parece confirmar esta última hipótesis. Al calcular los estadísticos tradicionales de dispersión para el indicador a nivel de clases de actividad y respecto de los grupos antes definidos (grupo globalizado y no globalizado), se observa un incremento en todos los casos. El mayor aumento se produce en el grupo no globalizado como resultado de una gran 
variedad de comportamientos en materia de inversión y cambio tecnológico, y donde predomina un fenómeno de obsolescencia y desindustrialización (en 16 de las 30 clases consideradas cayó la producción en términos reales y a pesar de que en 10 actividades del grupo se redujo el tiempo de trabajo, 10 clases registraron descensos en su productividad laboral en el período bajo estudio).

Por su parte, la tendencia de la desviación estándar del indicador para el grupo globalizado y el total del sector registra un alza del 52,2\% al comparar 2008 con 1994, mientras que la referida al coeficiente de variación es de un 23,3\% y un 20,6\%, respectivamente. Existen, sin embargo, dos subperíodos bien diferenciados. En el lapso inicial (1994-2002), luego de la entrada en vigor del TLCAN y de un acelerado proceso de apertura comercial y financiera de la economía, la heterogeneidad estructural se expande en forma rápida en el sector, pero en mayor medida dentro del grupo globalizado, que concentra a las industrias exportadoras privilegiadas por las nuevas medidas de política pública (las tasas de crecimiento promedio anual de la desviación estándar y del coeficiente de variación son de $8,3 \%$ y $6,4 \%$, respectivamente, para el sector en su conjunto; de $9,7 \%$ y $6,7 \%$ respecto del grupo globalizado, y de $3,7 \%$ y $3,3 \%$ del no globalizado). En un segundo período de relativa estabilización y después de la depuración de gran parte del aparato productivo nacional, la tendencia una vez más liderada por las empresas globalizadas se invierte tras alcanzar un auge en 2002, siendo que las tasas de crecimiento promedio anual de la desviación estándar y del coeficiente de variación son negativas entre 2002 y $2008(-4,1 \%$ y $-4,4$ para el sector, y $-2,6 \%$ y $-4,5$ para el grupo globalizado) (véanse los gráficos 1 y 2).

Diversos elementos ayudan a explicar las crecientes brechas entre los niveles de productividad laboral de las clases de actividad electromecánicas y sus tiempos en el país. Primeramente, luego de la apertura comercial, el proceso de inserción global de las industrias líderes del patrón de especialización sectorial significó mayores grados de heterogeneidad estructural, sobre todo dentro del grupo globalizado. La entrada o despegue de un número reducido de grandes compañías exportadoras altamente tecnificadas —en su mayoría subsidiarias de multinacionales extranjeras-coexistió con la incapacidad de otras muchas industrias locales para ser competitivas en el ámbito internacional, y con el ya mencionado desplazamiento de proveedores locales por importaciones, bajo el impulso y amparo de los programas nacionales de fomento a las exportaciones consistentes en facilitar la adquisición en el exterior de partes e insumos para ser incluidos en los bienes exportados. Al respecto, Unger señalaba que "la industria mexicana consolida estructuras oligopólicas cada vez más concentradas, debido a la influencia de las grandes ET (Empresas Transnacionales) y los grandes conglomerados nacionales de orientación exportadora" (Unger, 2001, pág. 100).

GRÁFICO 1 Evolución de la desviación estándar de la productividad laboral a nivel
de clases de actividad y por grupos de industrias, 1994-2008
(En pesos mexicanos de diciembre de 2003)

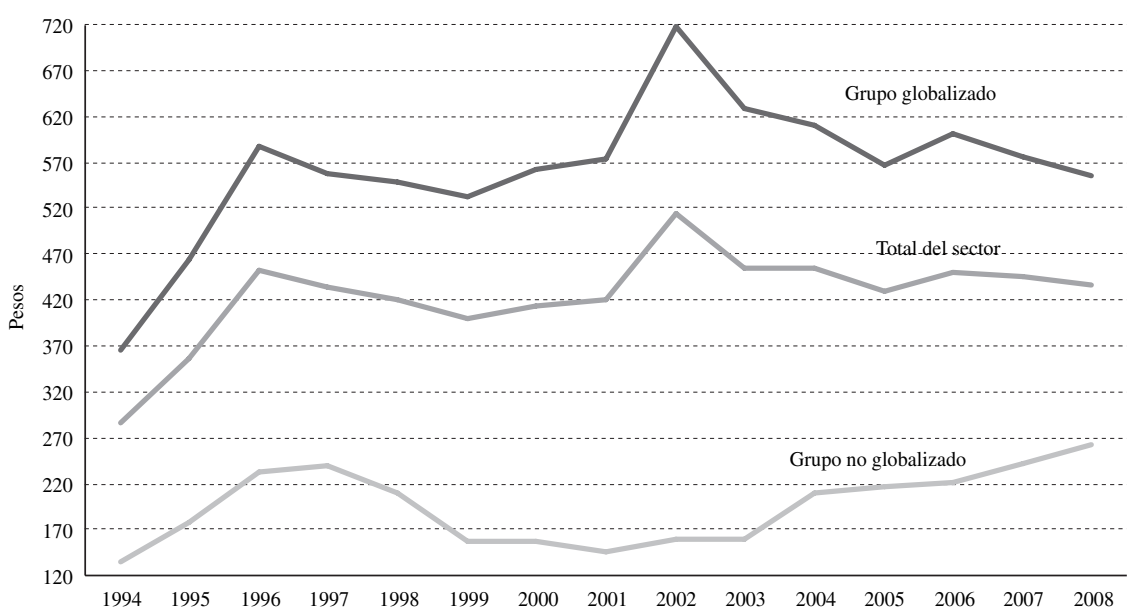

Fuente: elaboración propia sobre la base de datos de Instituto Nacional de Estadística y Geografía (INEGI), "Encuesta Industrial Mensual (EIM). Clasificación Mexicana de Actividades y Productos (CMAP), 205 clases de actividad económica”, 2013. 
GRÁFICO 2

Evolución del coeficiente de variación de la productividad laboral a nivel de clases de actividad y por grupos de industrias, 1994-2008

(Coeficientes calculados a partir de cifras expresadas en pesos mexicanos de diciembre de 2003)

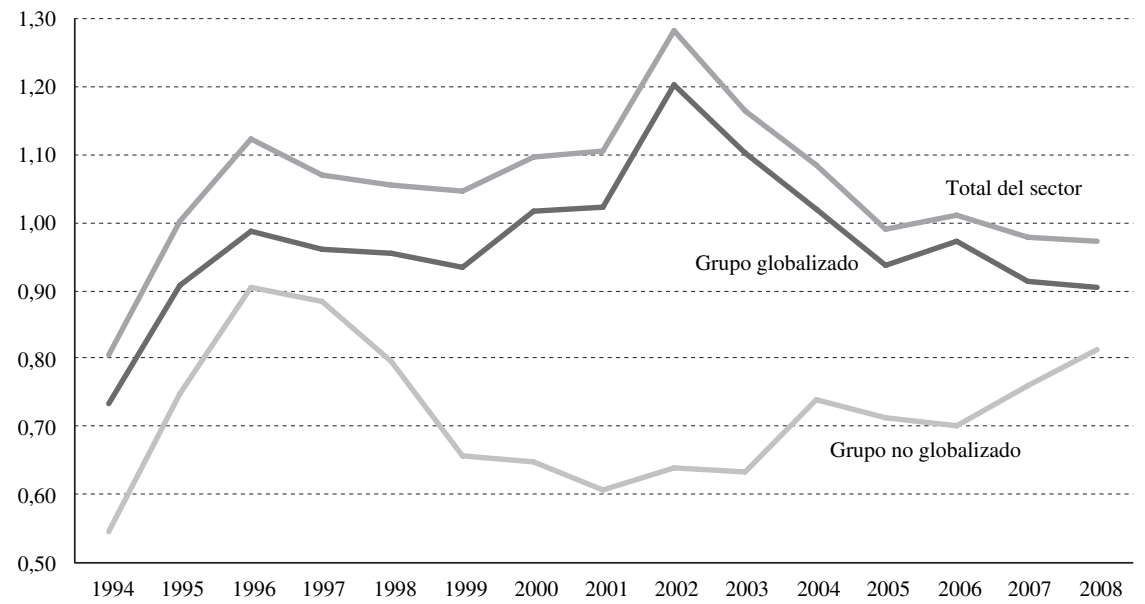

Fuente: elaboración propia sobre la base de datos de Instituto Nacional de Estadística y Geografía (INEGI), "Encuesta Industrial Mensual (EIM). Clasificación Mexicana de Actividades y Productos (CMAP), 205 clases de actividad económica”, 2013.

De igual forma, se produjo una reconversión en ciertas ramas con el fin de adaptarse tanto a los requerimientos establecidos por la "gobernanza" de las redes globales de producción, como a la realización de tareas con diferentes contenidos factoriales y esencialmente de ensamblaje. Víctimas de la competencia proveniente de las importaciones en el mercado local, la mayor parte de las pequeñas y medianas empresas (pymes), así como segmentos industriales enteros quebraron y desaparecieron, lo que se tradujo en una depuración del aparato productivo nacional. Al sintetizar dicha transformación, Capdevielle menciona que: "Se modificó la composición de la producción manufacturera, debido, por una parte, a que los sectores económicos que producían para la exportación se especializaron en determinados segmentos de la cadena de valor, y a causa, al mismo tiempo, de que la producción local fue sustituida por importaciones, gracias a la apertura y a la disponibilidad de divisas suscitada por la nueva forma de inserción en el comercio" (Capdevielle, 2005, pág. 108).

Es en este nuevo contexto de elevada concentración de los mercados, y en un segundo período (20032008), que los grados de heterogeneidad se reducen en el seno del grupo globalizado con presencia de una acotada difusión tecnológica y de capacidades dentro de las actividades líderes. Paralelamente, al no existir un flujo de conocimientos fuera de la red global, como tampoco externalidades positivas significativas, ni un aprendizaje organizacional generalizado, las brechas continuaron ampliándose en términos de eficiencia a un ritmo incluso mayor en las industrias residuales del grupo no globalizado, sumergido en un auténtico proceso de desindustrialización. Cabe resaltar que esta periodización, si bien con tendencias contrarias en los subperíodos considerados, es consistente con los hallazgos obtenidos en trabajos anteriores para el conjunto de la manufactura mexicana (Vázquez, 2013). 


\section{IV}

\section{Desindustrialización y cambio estructural}

En el marco de la desindustrialización de las actividades dedicadas al mercado interno, dos elementos tienden a corroborar la hipótesis antes postulada con relación a la ausencia de un cambio dinamizador del conjunto de la estructura del sector metalmecánico mexicano. Primero, la mayor heterogeneidad en términos tecnológicos y de capacidades y, en segundo término, la concentración de la capacidad productiva - tanto en un pequeño número de clases (sobre todo relacionadas con el ensamblaje), como dentro de estas clases - en unas cuantas grandes empresas insertas en redes globales de producción y beneficiadas por las medidas de política pública implementadas a raíz de la apertura comercial. En consecuencia, en esta sección se procura evaluar los determinantes de las evoluciones observadas en la productividad laboral de las distintas actividades, con el fin de confirmar, por una parte, la concentración de los avances de eficiencia en unas pocas clases globalizadas y, por otra, la escasa participación del desplazamiento del factor trabajo hacia usos más eficientes en las mejoras registradas.

Mediante una metodología estándar de tipo diferencial-estructural, técnica descriptiva comúnmente usada en este tipo de trabajos para descomponer las variaciones de la productividad (efecto total) en dos puntos en el tiempo: por una parte, un efecto relacionado con el cambio estructural, es decir, con el desplazamiento de los factores productivos hacia usos más eficientes (efecto estructural), y por otra, un efecto ligado a los cambios ocurridos dentro de cada actividad que pueden asociarse con el progreso técnico (efecto intrínseco); a continuación, utilizando la base de información presentada en la primera sección del trabajo, se descomponen los incrementos de la productividad laboral ocurridos en el sector entre 1994 y 2008. Sobra decir que los efectos pueden ser negativos cuando el desplazamiento de factores se realiza hacia actividades de menor productividad (efecto estructural), o cuando se producen disminuciones en la productividad laboral por motivos de obsolescencia tecnológica o en las formas de organización en el interior de las distintas actividades (efecto intrínseco).

La formulación matemática de esta descomposición, que se aplica para comparar los valores del indicador de las 53 clases en dos momentos en el tiempo (1994 y 2008), es la siguiente:

$$
\begin{gathered}
\left(P^{2008}-P^{1994}\right) \\
=\sum_{i=1}^{n}\left[\left(P_{i}^{2008}-P_{i}^{1994}\right) \cdot\left(S_{i}^{1994}+S_{i}^{2008}\right) / 2\right] \\
+\sum_{i=1}^{n}\left[\left(S_{i}^{2008}-S_{i}^{1994}\right) \cdot\left(P_{i}^{1994}+P_{i}^{2008}\right) / 2\right]
\end{gathered}
$$

donde $P_{i}$ es la productividad en la actividad $i(i=1,2, \ldots n)$ y $S_{i}$ es la participación de la actividad $i(i=1,2, \ldots n)$ en la población activa total empleada en el sector. El primer término del lado derecho de la ecuación (1) representa la variación de la productividad laboral ocurrida debido a los cambios en la productividad intrínseca de las $n$ clases de actividad (efecto intrínseco). El segundo término indica el aporte de la recomposición de la fuerza de trabajo (efecto estructural) (CEPAL, 2007).

Los resultados del ejercicio son consistentes con el análisis realizado anteriormente. En el período 1994-2008 tan solo el incremento de la productividad laboral en el ensamble automotriz (clase 384110) representa el 83,7\% del registrado en el conjunto del grupo globalizado y el $71,4 \%$ del aumento del indicador para el total del sector. Del aporte de esta actividad, el efecto intrínseco, atribuible a las mejoras tecnológicas y organizativas dentro de la clase, explica el 90,9\% de dicha mejora, siendo residual el efecto estructural en los avances obtenidos. Por su parte, en las actividades ligadas a la fabricación de insumos para el ensamblaje automotriz, el proceso modernizador es por lo demás débil (la suma de los efectos intrínsecos es de 23 pesos mexicanos de diciembre de 2003 en el lapso considerado $)^{9}$, destacándose el caso de la clase 384122 , proveedora de motores y partes, en la que los dos efectos calculados son negativos, lo que denota la falta de una difusión tecnológica y de capacidades en el interior de la rama, conducente a una ampliación de las brechas en términos de eficiencia entre la industria terminal y sus proveedores locales potenciales (véase el cuadro 5).

\footnotetext{
9 Se sumaron los efectos intrínsecos relativos a la evolución de la productividad laboral de las clases 384121, 384122, 384123, 384124, 384125 y 384126.
} 
CUADRO 5

Determinantes de la evolución de la productividad laboral a nivel de clases de actividad y por grupos de industrias, 1994-2008

(En pesos mexicanos de diciembre de 2003)

\begin{tabular}{|c|c|c|c|c|c|c|c|}
\hline \multicolumn{4}{|c|}{ Grupo no globalizado } & \multicolumn{4}{|c|}{ Grupo globalizado } \\
\hline Clase de actividad & $\begin{array}{c}\text { Efecto } \\
\text { intrínseco }\end{array}$ & $\begin{array}{l}\text { Efecto } \\
\text { estructural }\end{array}$ & Efecto total & Clase de actividad & $\begin{array}{c}\text { Efecto } \\
\text { intrínseco }\end{array}$ & $\begin{array}{c}\text { Efecto } \\
\text { estructural }\end{array}$ & Efecto total \\
\hline 381100 & 5,1 & $-0,1$ & 5,0 & 384110 & 153,1 & 15,3 & 168,5 \\
\hline 381201 & 3,9 & $-3,7$ & 0,2 & 384121 & 12,2 & $-2,5$ & 9,8 \\
\hline 381202 & $-0,4$ & $-0,8$ & $-1,2$ & 384122 & $-3,6$ & $-1,8$ & $-5,4$ \\
\hline 381203 & 1,5 & $-0,3$ & 1,2 & 384123 & 7,2 & 4,3 & 11,5 \\
\hline 381300 & $-0,1$ & $-0,7$ & $-0,8$ & 384124 & 1,6 & 0,5 & 2,1 \\
\hline 381401 & $-0,6$ & 0,1 & $-0,5$ & 384125 & 1,7 & $-0,1$ & 1,5 \\
\hline 381404 & 0,4 & 1,3 & 1,7 & 384126 & 3,8 & 5,8 & 9,6 \\
\hline 381405 & $-0,3$ & $-0,4$ & $-0,7$ & 382302 & $-3,3$ & $-4,3$ & $-7,6$ \\
\hline 381407 & 9,7 & $-6,3$ & 3,4 & 383101 & 5,6 & 5,2 & 10,8 \\
\hline 381408 & 0,3 & $-1,6$ & $-1,2$ & 383102 & 0,6 & 0,1 & 0,7 \\
\hline 381409 & 0,6 & $-0,2$ & 0,4 & 383103 & 0,5 & 5,7 & 6,2 \\
\hline 381410 & $-0,1$ & 0,3 & 0,2 & 383107 & 6,7 & $-5,8$ & 0,9 \\
\hline 381412 & 8,2 & 4,1 & 12,3 & 383108 & $-0,1$ & 0,2 & 0,1 \\
\hline 382101 & 2,2 & 1,1 & 3,3 & 383109 & 8,9 & $-8,8$ & 0,1 \\
\hline 382102 & 0,5 & $-0,7$ & $-0,1$ & 383110 & $-1,0$ & 0,0 & $-1,0$ \\
\hline 382103 & 0,7 & 2,3 & 3,0 & 383201 & $-2,0$ & $-3,1$ & $-5,1$ \\
\hline 382104 & 0,1 & $-0,2$ & 0,0 & 383204 & $-2,4$ & 1,0 & $-1,4$ \\
\hline 382106 & 0,2 & $-1,3$ & $-1,1$ & 383205 & 0,9 & $-4,2$ & $-3,3$ \\
\hline 382202 & 0,7 & $-1,3$ & $-0,6$ & 383206 & 0,1 & $-0,6$ & $-0,5$ \\
\hline 382203 & 0,0 & $-0,3$ & $-0,3$ & 383301 & 0,2 & 2,1 & 2,3 \\
\hline 382205 & 1,4 & $-0,3$ & 1,1 & 383302 & 2,4 & 1,5 & 3,8 \\
\hline 382206 & 2,9 & 5,4 & 8,3 & 383303 & $-0,2$ & $-0,7$ & $-0,9$ \\
\hline 382207 & $-0,2$ & 0,1 & 0,0 & 383304 & 0,7 & $-1,9$ & $-1,2$ \\
\hline 384201 & 0,4 & $-0,3$ & 0,1 & Total globalizado & 193,5 & 7,8 & 201,4 \\
\hline 384202 & 0,6 & 0,7 & 1,3 & & & & \\
\hline 384203 & $-0,8$ & 0,2 & $-0,5$ & & & & \\
\hline 385001 & $-0,2$ & 0,0 & $-0,2$ & & & & \\
\hline 385002 & 0,0 & 0,0 & 0,0 & & & & \\
\hline 385004 & $-0,1$ & 0,7 & 0,6 & & & & \\
\hline 385005 & $-0,2$ & $-0,1$ & $-0,3$ & & & & \\
\hline Total no globalizado & 36,5 & $-2,0$ & 34,5 & & & & \\
\hline Total sector & 230,0 & 5,9 & 235,9 & & & & \\
\hline
\end{tabular}

Fuente: elaboración propia sobre la base de datos del Instituto Nacional de Estadística y Geografía (INEGI), "Encuesta Industrial Mensual (EIM). Clasificación Mexicana de Actividades y Productos (CMAP), 205 clases de actividad económica", 2013.

Por su parte, la contribución del grupo no globalizado al incremento de la productividad laboral del sector durante el período es reducida, ya que representa un $14,6 \%$ de los 235,9 pesos mexicanos de diciembre de 2003. Dentro de este grupo, la concentración de las mejoras de eficiencia es no obstante también notable; la suma de las clases 381412: "Galvanoplastia en piezas metálicas", y 382206: "Fabricación de equipos y aparatos de aire acondicionado, refrigeración y calefacción", representa el 59,8\% del aumento del indicador en el grupo no globalizado. Asimismo, en el interior de este grupo destacan de forma sintomática los resultados de la actividad "Fabricación de envases y productos de hojalata, lámina y aluminio" (381407), que como otras clases, y a pesar de registrar un incremento de su productividad laboral en el período, tiene pérdidas de eficiencia por expulsión de mano de obra (las horas-hombre trabajadas en la clase 381407 se redujeron de 19.458 en el año 1994 a 11.082 en el año 2008).

Al respecto, la evidencia es contundente en lo relativo al nulo aporte del cambio estructural —entendido aquí como el desplazamiento del factor trabajo en dirección de usos más eficientes- a la evolución del indicador, tanto a nivel de las 53 clases como de los dos grupos establecidos. Del incremento total de la productividad laboral, el efecto estructural solo explica 5,9 pesos de los 235,9 pesos en el sector en su conjunto, es responsable de 7,8 pesos de los 201,4 pesos en el grupo globalizado, y es incluso negativo en el no globalizado (véase el cuadro 5). De hecho, en 29 de las 53 clases consideradas, el efecto estructural es efectivamente negativo. En el caso del ensamblaje automotriz, que concentra las mejoras 
tecnológicas y organizativas del sector, la atracción de mano de obra aporta menos del 10\% del aumento de su productividad laboral en el lapso bajo estudio $(9,1 \%)$, lo que corrobora la incapacidad antes mencionada de las industrias líderes de generar empleo a objeto de compensar los puestos de trabajo destruidos en las actividades no competitivas.

En términos generales, los hallazgos obtenidos contradicen uno de los principales argumentos teóricos de la implementación de la estrategia de apertura comercial, a saber, la existencia de un proceso de destrucción creativa, en el que los empleos perdidos en las actividades no exportadoras — perjudicadas por las medidas de política pública implementadas - son generados en compensación por las industrias líderes del patrón de especialización. Al revisar la base de datos utilizada, efectivamente se constata que, al comparar el año 2008 con el año 1994, el sector electromecánico en el que se encuentran insertas las industrias pilares del modelo exportador manufacturero mexicano, registró una pérdida neta en su población ocupada de 370.631 trabajadores, es decir, una reducción de 58.251 horas-hombre trabajadas.

\section{V}

\section{Especialización productiva y competitividad dinámica}

En cuanto al desarrollo de la actividad exportadora, las ventas al extranjero del sector electromecánico mexicano tuvieron un pronunciado crecimiento de 380,2\% al comparar 2008 con 1994; sin embargo y en contraposición, sus importaciones registraron un incremento muy similar $(358,7 \%)$. De hecho, en los 15 años del período señalado, el saldo comercial acumulado del sector fue negativo en 76.000 millones de dólares (véase el gráfico 3). A manera de ejemplo, en el año 2008 las exportaciones del sector alcanzaron los 169.600 millones de dólares, repartidos en 131.900 millones de dólares del grupo globalizado y 37.700 mil millones de dólares del grupo no globalizado. A consecuencia de la dinámica establecida a raíz de la apertura, el sector tuvo un déficit externo de 9.900 millones de dólares en el año; no obstante, mientras que en el caso del primer grupo el saldo comercial fue positivo, en el grupo no globalizado el balance fue negativo. La desindustrialización en el grupo no globalizado y el consiguiente crecimiento de las cuotas de mercado interno ganadas por las importaciones se combinaron, entonces, con una lógica organizacional de las industrias líderes del patrón de especialización insertas en redes globales de producción, marcada por la importación de la mayoría de los insumos incluidos en los productos exportados.

Con el fin de evaluar desde una perspectiva dinámica la evolución de la competitividad del sector electromecánico mexicano, se construyó una segunda base de datos en que se reclasifican, en términos de la Clasificación Mexicana de Actividades y Productos
(CMAP) del Instituto Nacional de Estadística y Geografía (INEGI), 1.345 productos identificados como parte del sector en la Clasificación SA92 (véase el anexo). A partir de este insumo, se aplicó a 1.199 de estos bienes ${ }^{10}$ una extensión de la metodología elaborada para el programa MAGIC por la Sede Subregional de la CEPAL en México. Este ejercicio permite caracterizar las ventas sectoriales al extranjero siguiendo su desempeño (dinámicas o estancadas) y en función del cambio en la participación relativa de la demanda mundial de cada mercancía en el comercio total de bienes (creciente o en retroceso) (CEPAL, 2006). En el programa MAGIC se establece entonces una tipología que clasifica las exportaciones en estrellas nacientes (EN), estrellas menguantes (EM), oportunidades pérdidas $(\mathrm{OP})$ y retirada $(\mathrm{R})^{11}$.

\footnotetext{
10 Debido a la inexistencia de la información estadística necesaria en el caso de 146 productos, el ejercicio se realizó para 1.199 de los 1.345 productos presentes en la base de datos elaborada.

11 "Estrella naciente" significa que las importaciones del producto aludido aumentaron en el mercado estadounidense y que el país en cuestión incrementó su participación en las importaciones totales que los Estados Unidos de América hacen de ese producto. "Estrella menguante" denota que las importaciones del producto referido disminuyeron en el mercado estadounidense y que el país en cuestión acrecentó su participación en las importaciones totales que los Estados Unidos de América hacen de ese producto. "Oportunidad pérdida" significa que las importaciones del producto específico se incrementaron en el mercado estadounidense y que el país en cuestión disminuyó su participación en las importaciones totales que los Estados Unidos de América hacen de ese producto. "Retirada" significa que las importaciones de tal producto se redujeron en el mercado estadounidense y que el país en cuestión vio aminorada su participación en las importaciones totales
} 
GRÁFICO 3

Exportaciones, importaciones y saldos comerciales acumulados por grupos de industrias, 1994-2008

(En miles de millones de dólares)

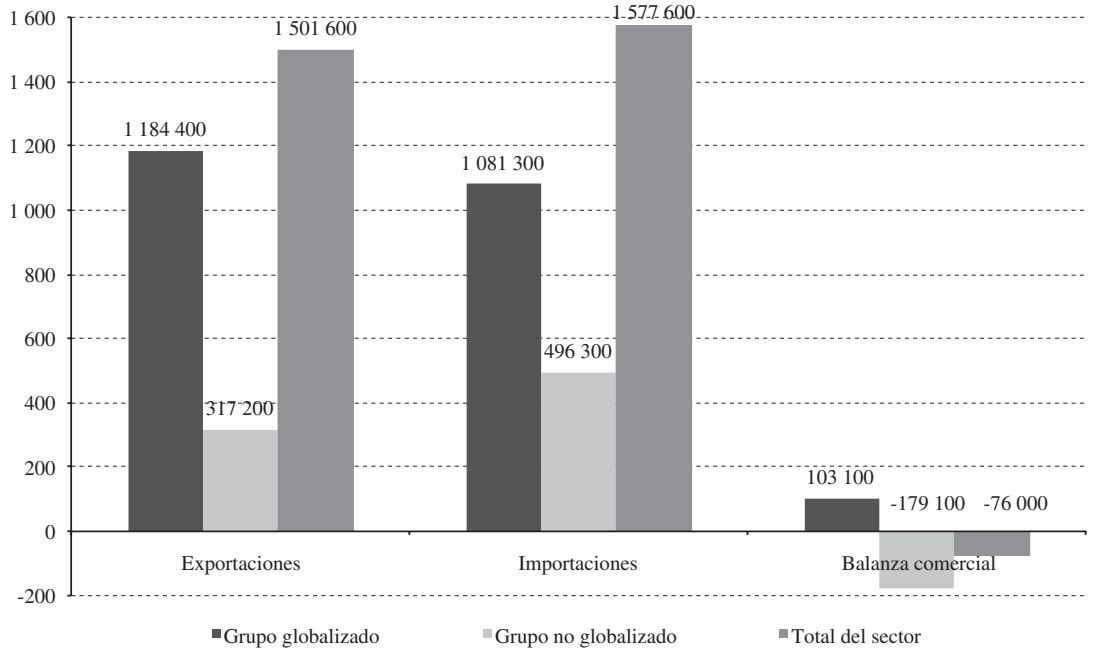

Fuente: elaboración propia sobre la base de datos de las Naciones Unidas, Base de Datos Estadísticos sobre el Comercio de Mercaderías (COMTRADE).

El ejercicio fue realizado comparando los años 1994 y 2008, y los resultados se presentan en el cuadro 6, donde el valor de la sumatoria de las exportaciones para cada tipología fue calculado con respecto al año 2008. A nivel del total sectorial, se verifica el liderazgo del sector electromecánico en el seno del patrón de especialización exportador mexicano y su inserción en redes globales de producción a través de la venta de bienes dinámicos, que en el período examinado

que los Estados Unidos de América hacen de ese producto (Cordero, 2010, pág. 26). En el ejercicio se tomó como referencia el mercado mundial en lugar de limitarlo al de los Estados Unidos de América y se compararon los valores de exportación de los años 1994 y 2008. registraron un incremento de su participación en el comercio mundial de productos. De los 1.199 bienes considerados, en 710 de ellos, que representan el $82,8 \%$ del valor total de las ventas al exterior del sector en 2008 , el país aumentó su cuota en el mercado internacional ${ }^{12}$. De estos, 215 productos - que concentran el $45,5 \%$ de las exportaciones totales en dicho año-fueron EN, es decir, mercancías con un intercambio en crecimiento en los mercados globales en que el país amplió su

12 De aquí en adelante, con el fin de dar consistencia al ejercicio realizado, los totales sectoriales provienen de la sumatoria de las exportaciones de los 1.199 productos considerados.

CUADRO 6

Tipología de los productos exportados por grupos de industrias en 2008 (En número y millones de dólares)

\begin{tabular}{|c|c|c|c|c|c|c|}
\hline Grupos & & $\begin{array}{l}\text { Estrella } \\
\text { naciente }\end{array}$ & $\begin{array}{l}\text { Estrella } \\
\text { menguante }\end{array}$ & $\begin{array}{l}\text { Oportunidad } \\
\text { perdida }\end{array}$ & Retirada & Total \\
\hline \multirow[t]{2}{*}{ Grupo globalizado } & Número de productos & 54 & 128 & 40 & 96 & 318 \\
\hline & Valor & 61917400 & 47432600 & 12067700 & 8750500 & 130168200 \\
\hline \multirow[t]{2}{*}{ Grupo no globalizado } & Número de productos & 161 & 367 & 100 & 253 & 881 \\
\hline & Valor & 14377500 & 15046800 & 4725200 & 3200800 & 37350300 \\
\hline \multirow[t]{2}{*}{ Total del sector } & Número de productos & 215 & 495 & 140 & 349 & 1199 \\
\hline & Valor & 76294900 & 62479400 & 16792900 & 11951300 & 167518500 \\
\hline
\end{tabular}

Fuente: elaboración propia sobre la base de datos de las Naciones Unidas, Base de Datos Estadísticos sobre el Comercio de Mercaderías (COMTRADE). 
participación relativa. La evidencia estadística denota entonces una competitividad sostenible de las redes globales de producción en que se insertan estas industrias "líderes" de la manufactura mexicana, así como la elevada concentración de su dinamismo exportador en un número reducido de mercancías.

En cuanto a los grupos construidos, resaltan los altos grados tanto de diversificación como de competitividad dinámica de las exportaciones del grupo no globalizado. En 2008 este grupo, a pesar de ser responsable de solo el $22,3 \%$ de las exportaciones sectoriales totales, vendió al extranjero 881 productos de los 1.199 registrados. El 78,8\% del valor de estas ventas corresponde a mercancías en las que estas industrias incrementaron su cuota de mercado global y el 38,5\% de su valor entró en la tipología de "estrellas nacientes" (EN). Como se observa en el cuadro 6, algunas de estas cifras relativas son similares en el caso del grupo globalizado (318 productos de los 1.199 registrados, representando la suma de EN $(47,6 \%)$ y EM $(36,4 \%)$ el $84 \%$ del valor de las exportaciones totales del grupo). Pareciera entonces que en ciertas industrias no insertas en redes globales de producción, y en algunos casos con presencia en el mercado interno, aún existen las capacidades organizativas y tecnológicas necesarias para competir en el ámbito global.

$\mathrm{Al}$ analizar los más importantes productos de exportación en 2008 , se confirma a la vez la elevada concentración de la actividad en un número reducido de tareas, así como el aspecto restringido del dinamismo exportador alcanzado. Los 50 principales productos de exportación representan el 71,5\% del monto total de las exportaciones del sector; los 10 primeros - todos ellos relativos a la fabricación de equipo eléctrico-electrónico y de computación o vinculados a la industria automotrizsignifican $43,3 \%$, y tan solo 3 bienes $^{13}$ de los 1.199 considerados explican el $28,4 \%$ de las ventas sectoriales al extranjero. Asimismo, al representar estos 50 productos en un diagrama en función de las tipologías establecidas, los resultados no difieren mucho de lo observado para el

${ }^{13}$ En la clasificación internacional SA92, estos bienes son: 852810 , Receptores, monitores, proyectores de televisión a color; 870323 , Automóviles de pasajeros con motor de encendido de 1.500 a $3.000 \mathrm{cc}$; y 852520, Aparatos de transmisión-recepción de radio, televisión, etc. conjunto de la información de la base de datos, aunque como era de esperar — dado el liderazgo de dichas mercancías en el patrón de especialización manufacturero mexicano- las cifras son un poco más elevadas en la categoría EN, que se traducen en un aumento en las cuotas de mercado global en bienes dinámicos en el período de estudio. En términos del valor de las ventas al exterior de estos 50 productos, el 50,4\% está catalogado como EN (19 productos), el 34,3\% como EM (16 productos), un $6,9 \%$ como op ( 8 productos) y un $8,4 \%$ como $R$ (7 productos) (véase el gráfico 4 ).

Un apunte final tiene que ver con las características de la metodología utilizada y con los rasgos comúnmente presentes en el cálculo de los indicadores que existen para evaluar la competitividad. En el caso de México, el acelerado proceso de apertura comercial implementado a partir de los años ochenta por la política pública se tradujo en un crecimiento generalizado de las exportaciones nacionales, superior al promedio registrado por los intercambios internacionales. Este hecho explica en parte el aumento de las participaciones de los productos mexicanos "líderes" del patrón de especialización en los mercados globales. Otra tendencia del contexto mundial expone a su vez los resultados obtenidos; los bienes dinámicos, por definición, incrementan en el tiempo su contribución al comercio internacional, por lo que existe un sesgo en la metodología utilizada que favorece las probabilidades de que el país analizado evolucione aparentemente en dirección a estructuras más competitivas. En el caso de la metodología desarrollada por la CEPAL, las tipologías establecidas se construyen valorando el comercio de bienes fabricados a partir de toda una serie de componentes e insumos producidos en distintas latitudes. Al no poder considerar el valor agregado doméstico contenido en las mercancías, la metodología cifra los intercambios en términos del precio final de los bienes, atribuyendo de manera imprecisa capacidades, inversiones en capital y horas de trabajo a los participantes del comercio. En el caso de países con perfiles productivos de tipo maquilador como el mexicano, los ejercicios tienden a sobrevalorar la evolución de la estructura exportadora, tal y como lo evidencian tanto los saldos comerciales negativos de la actividad como sus escasos efectos de arrastre antes documentados. 
Tipología de los 50 productos principales exportados por el sector electromecánico mexicano, 2008

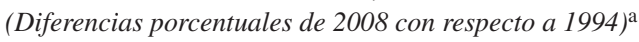

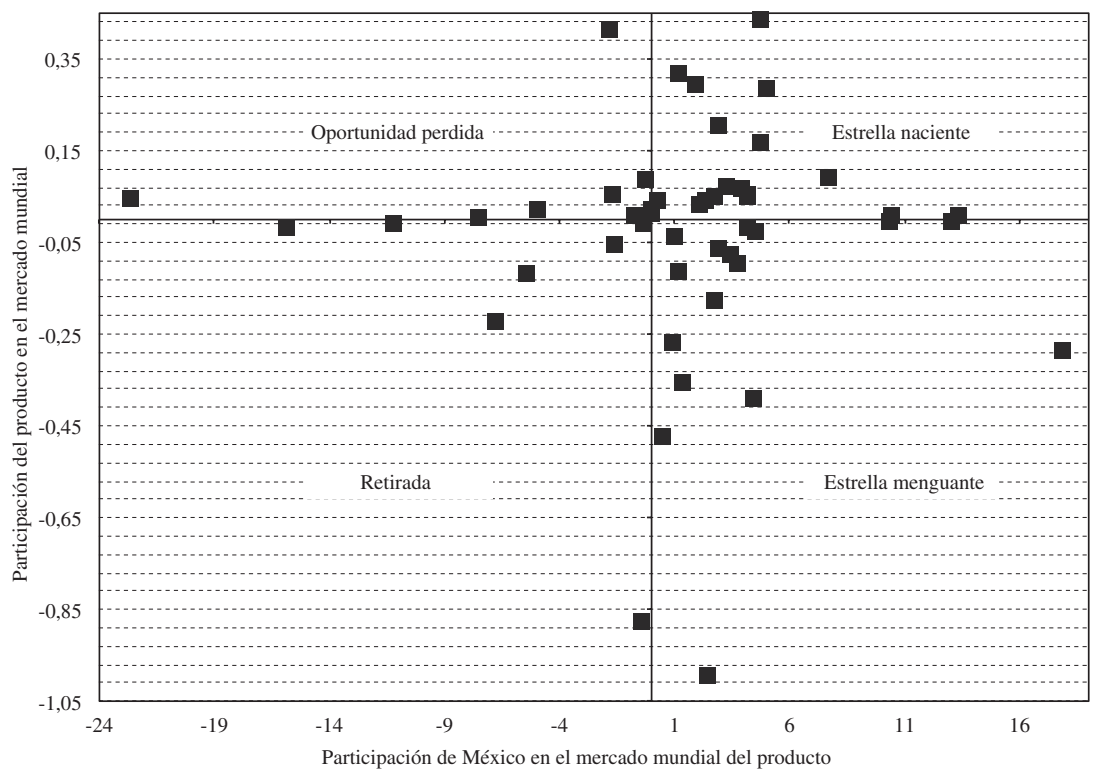

Fuente: elaboración propia sobre la base de datos de las Naciones Unidas, Base de Datos Estadísticos sobre el Comercio de Mercaderías (COMTRADE).

a En la categoría 870422 se utilizó el valor del año 1995, debido a que no existen datos para 1994 en la fuente de información.

\section{VI}

\section{Conclusiones}

El cálculo de diferentes indicadores y ejercicios estadísticos, realizados a partir de una extensa recopilación de datos provenientes de distintas fuentes de información, permite confirmar algunas tendencias observadas en la evolución estructural del sector electromecánico mexicano, pilar del patrón de especialización exportador nacional. Primeramente, se observa una progresiva concentración de la oferta y de las mejoras en términos de eficiencia en un número reducido de firmas filiales de empresas transnacionales de la rama del ensamblaje automotriz, lo que ha conllevado la ruptura de los eslabonamientos locales de valor. En segunda instancia, se destaca la incapacidad de las industrias líderes del modelo con vocación exportadora para generar empleo de forma sustantiva y producir efectos considerables de arrastre y de difusión en términos tecnológicos y organizativos.

A nivel estructural, se verifica también la hipótesis planteada sobre la expansión de la heterogeneidad intrasectorial que se produce, en un primer período, tras la apertura comercial en el seno de las actividades globalizadas y, en un segundo lapso, una vez depurado el aparato productivo, en las clases no insertas en redes globales de producción que, si bien sumidas como grupo en un proceso de obsolescencia y desindustrialización, mantienen en algunos casos la capacidad de ser competitivas en el ámbito global. Asimismo, la evidencia es contundente en cuanto a la ausencia de un cambio estructural significativo que permita el desplazamiento del factor trabajo hacia usos de mayor productividad, descalificando parcialmente el argumento teórico ortodoxo con que se defiende la capacidad del mercado para asignar de manera eficiente los recursos en la economía.

En lo que respecta a la competitividad global, la imposibilidad de disponer de series estadísticas largas y consistentes, que cuantifiquen el comercio internacional en términos del valor agregado presente en los bienes, 
entre otros factores, impide evaluar integralmente el desempeño exportador del sector. Los resultados obtenidos con estas limitantes arrojan evidencia de una actividad dinámica sostenible de las redes globales de producción en que se encuentran insertas las empresas residentes en el país, líderes del modelo. Cabe notar, sin embargo, tanto el elevado grado de diversificación y dinamismo presente en las exportaciones de industrias no insertas en redes globales de producción, como la detección en algunas clases eminentemente globalizadas de la rama electrónica de un fenómeno de competitividad "espuria", caracterizado por crecientes ventas al extranjero aparejadas de una evolución desfavorable de los niveles de productividad laboral.

En este sentido, el papel y los resultados de la política pública implementada en México a partir de los años ochenta, orientada según los lineamientos teóricos ortodoxos, parecen confirmar las tesis de algunos autores presentados a título introductorio. Tal como postulan Coe y otros (2004), las medidas establecidas han moldeado las capacidades locales en función de los requerimientos competitivos de las redes globales de producción, teniendo como consecuencia, entre otras, una redoblada especialización de las industrias líderes en tareas intensivas en mano de obra (Deardoff, 1979). La incapacidad de la estrategia de generar un cambio estructural significativo en términos del desarrollo productivo nacional conduce, no obstante, a replantear los lineamientos elegidos. Una propuesta alternativa, tendiente a desarrollar las complementariedades estructurales estratégicas requeridas para incrementar la densidad y los grados de diversificación del sistema productivo, pudiera centrarse entonces en el impulso al mercado interno y, en primera instancia, en la satisfacción de las necesidades básicas de la población.

ANEXO

CUADRO A.1

Características de la base de datos sobre la estructura productiva del sector electromecánico mexicano

\begin{tabular}{|c|c|c|c|c|}
\hline Unidades & Variables & $\begin{array}{l}\text { Cobertura } \\
\text { temporal }\end{array}$ & $\begin{array}{l}\text { Cobertura } \\
\text { sectorial }\end{array}$ & Fuentes \\
\hline $\begin{array}{l}\text { Pesos de diciembre de } 2003 . \\
\text { Los datos fueron deflactados } \\
\text { con el Índice Nacional de } \\
\text { Precios Productor (INPP) } \\
\text { del sector manufacturero, } \\
\text { calculado por el Banco de } \\
\text { México (BANXICO) (2011) }\end{array}$ & $\begin{array}{l}\text { Producción, } \\
\text { horas-hombre } \\
\text { trabajadas y su } \\
\text { cociente, indicador } \\
\text { de productividad } \\
\text { laboral }\end{array}$ & $\begin{array}{l}\text { Mensual } \\
\text { y anual. } \\
\text { Período } \\
\text { 1994-2008 }\end{array}$ & $\begin{array}{l}13 \text { ramas y } \\
53 \text { clases de } \\
\text { actividad }^{\mathrm{a}} \text {. } \\
28.620 \\
\text { datos en } \\
\text { total }\end{array}$ & $\begin{array}{l}\text { La necesidad de obtener series largas y } \\
\text { consistentes de tiempo que pudieran dar cuenta de } \\
\text { posibles transformaciones vinculadas a procesos } \\
\text { de cambio estructural, implicó que la única fuente } \\
\text { viable de los datos fuera la Encuesta Industrial } \\
\text { Mensual (EIM) del Instituto Nacional de Estadística } \\
\text { y Geografía (INEGI) (2013a) bajo la Clasificación } \\
\text { Mexicana de Actividades y Productos (CMAP) }\end{array}$ \\
\hline
\end{tabular}

Fuente: elaboración propia.

a El grupo globalizado contiene las 23 clases de actividad que forman parte de las ramas: 3841, "Industria automotriz" (7 clases); 3823 , "Fabricación y/o ensamble de máquinas de oficina, cálculo y procesamiento informático" (1 clase); 3831, "Fabricación y/o ensamble de maquinaria, equipo y accesorios eléctricos. Incluye para la generación de energía eléctrica" (7 clases); 3832 , "Fabricación y/o ensamble de equipo electrónico de radio, televisión, comunicaciones y de uso médico" (4 clases); 3833, "Fabricación y/o ensamble de aparatos y accesorios de uso doméstico. Excluye los electrónicos" (4 clases). Por su parte, el grupo no globalizado incluye las 30 clases de actividad que forman parte de las ramas; 3811, "Fundición y moldeo de piezas metálicas, ferrosas y no ferrosas" (1 clase); 3812 , "Fabricación de estructuras metálicas, tanques y calderas industriales. Incluso trabajos de herrería" (3 clases); 3813, "Fabricación y reparación de muebles metálicos" (1 clase); 3814, "Fabricación de otros productos metálicos. Excluye maquinaria y equipo" (8 clases); 3821 , "Fabricación, reparación y/o ensamble de maquinaria y equipo para fines específicos, con o sin motor eléctrico integrado. Incluye maquinaria agrícola" (5 clases); 3822, "Fabricación, reparación y/o ensamble de maquinaria y equipo para usos generales, con o sin motor eléctrico integrado. Incluye armamento" (5 clases); 3842, "Fabricación, reparación y/o ensamble de equipo de transporte y sus partes. Excluye automóviles y camiones" (3 clases); 3850, "Fabricación, reparación y/o ensamble de instrumentos y equipo de precisión. Incluye instrumental quirúrgico. Excluye los electrónicos" (4 clases). Las clases de actividad: 382301, 383202, 384204 y 385006 no fueron consideradas por no existir información referente a ellas en la encuesta a partir del año 2003. 


\section{Características de la base de datos sobre el desempeño externo del sector} electromecánico mexicano

\begin{tabular}{|c|c|c|c|c|}
\hline Unidades & Variables & $\begin{array}{l}\text { Cobertura } \\
\text { temporal }\end{array}$ & $\begin{array}{l}\text { Cobertura de } \\
\text { productos }\end{array}$ & Fuentes \\
\hline $\begin{array}{l}\text { Dólares de los } \\
\text { Estados Unidos } \\
\text { corrientes y } \\
\text { porcentajes }\end{array}$ & $\begin{array}{l}\text { - Exportaciones de México al mundo por } \\
\text { producto y grupo. } \\
\text { - Importaciones de México provenientes del } \\
\text { mundo por producto y grupo. } \\
\text { - Participación de las exportaciones mexicanas } \\
\text { de cada producto en el total nacional. } \\
\text { - Participación de México en el mercado } \\
\text { mundial por producto. } \\
\text { - Exportaciones mundiales totales por producto } \\
\text { y grupo. } \\
\text { - Participación de cada producto en las } \\
\text { exportaciones mundiales. } \\
\text { - Cambio en la participación de mercado de } \\
\text { México por producto. } \\
\text { - Cambio en la participación de exportaciones } \\
\text { mundiales por producto. } \\
\text { - Tipología MAGIC por producto. }\end{array}$ & $\begin{array}{l}\text { Anual. } \\
\text { Período } \\
\text { 1994-2008 }\end{array}$ & $\begin{array}{l}1345 \text { productos } \\
\text { identificados como } \\
\text { parte del sector bajo } \\
\text { la Clasificación del } \\
\text { Sistema Arancelario } \\
1992 \text { (SA92). } \\
161400 \text { datos en total }\end{array}$ & $\begin{array}{l}\text { ONU, base de datos del } \\
\text { COMTRADE. }\end{array}$ \\
\hline
\end{tabular}

Fuente: elaboración propia.

a A fin de estimar el valor de las exportaciones de las clases de actividad reagrupadas en la CMAP para el período 1994-2008, se diferenciaron los productos fabricados por el complejo electromecánico bajo la clasificación SA92. Al no existir equivalencias oficiales desagregadas entre los sistemas de clasificación industriales mexicanos y los comúnmente usados respecto del comercio internacional, se procedió a reclasificar de manera detallada los 1.345 productos a 6 dígitos de agregación encontrados en el SA92 en términos de las clases de actividad de la Clasificación Mexicana de Actividades y Productos (CMAP).

Bibliografía

Álvarez, M. (2002), "Cambios en la industria automotriz frente a la globalización: El sector de autopartes en México", Contaduría y Administración, $\mathrm{N}^{\circ}$ 206, México, D.F., Universidad Nacional Autónoma de México, julio.

Arndt, S. (2001), "Offshore sourcing and production sharing in preference areas", Fragmentation. New Production Patterns in the World Economy, S. Arndt y H. Kierzkowski (eds.), Oxford, Oxford University Press.

Arndt, S. y H. Kierzkowski (2001), "Introduction", Fragmentation. New Production Patterns in the World Economy, S. Arndt y H. Kierzkowski (eds.), Oxford, Oxford University Press.

BanXICo (Banco de México) (2011), "Estadísticas en línea. Índice de precios al productor" [en línea] http://www.banxico.org. $\mathrm{mx} /$ SieInternet/consultarDirectorioInternetAction.do?accion= consultarDirectorioCuadros\&sector=20\&sectorDescripcion $=$ $\%$ CDndices $\% 20 \mathrm{de} \% 20$ Precios $\% 20$ Productor $\% 20 \mathrm{y} \% 20 \mathrm{de} \% 20$ Comercio\%20Exterior\&locale $=$ es.

Capdevielle, M. (2005), "Globalización, especialización y heterogeneidad estructural en México", Heterogeneidad estructural, asimetrías tecnológicas y crecimiento en América Latina, M. Cimoli (ed.), Santiago de Chile, Comisión Económica para América Latina y el Caribe (CEPAL)/Banco Interamericano de Desarrollo (BID).

CEPAL (Comisión Económica para América Latina y el Caribe) (2007), "Progreso técnico y cambio estructural en América Latina", Documentos de Proyectos, $\mathrm{N}^{\circ} 136$ (LC/W.136), Santiago de Chile.

(2006), "Magic Plus. Module to Analyse the Growth of International Commerce" [en línea] http://www.cepal.org/ magic/noticias/software/9/27199/MAGIC\%20Plus.pdf.
Coe, N. y otros (2004), “'Globalizing' regional development: a global production networks perspective", Transactions of the Institute of British Geographers, vol. 29, № 4, Wiley, diciembre.

comtrade (Base de Datos Estadísticos sobre el Comercio de Mercaderías) (2012) [en línea] http://comtrade.un.org/db/.

Cordero, M. (2010), "Indicadores de comercio exterior: Subregión norte de América Latina, 2010", Documento de Trabajo (LC/MEX/L.995), México, D.F., Comisión Económica para América Latina y el Caribe (CEPAL).

Dawley, S. (2011), "Transnational corporations and local and regional development", Handbook of Local and Regional Development, A. Pike, A. Rodríguez-Pose y J.J. Tomaney (eds.), Londres, Routledge.

Deardoff, A. (1979), "Weak links in the chain of comparative advantage", Journal of International Economics, vol. 9, $\mathrm{N}^{\circ} 2$, Elsevier, mayo.

Durán, J. y M. Álvarez (2008), "Indicadores de comercio exterior y política comercial: Mediciones de posición y dinamismo comercial", Documentos de Proyectos, N 217 (LC/W.217), Santiago de Chile, Comisión Económica para América Latina y el Caribe (CEPAL).

Furtado, C. (1961), Desarrollo y subdesarrollo, México, D.F., Fondo de Cultura Económica.

Hernández, E. (2000), La competitividad industrial en México, México, D.F., Plaza y Valdés.

INEGI (Instituto Nacional de Estadística y Geografía) (2013a), "Encuesta Industrial Mensual (EIM). Clasificación Mexicana de Actividades y Productos (CMAP), 205 clases de actividad económica" [en línea] http://dgcnesyp.inegi.org.mx/cgi-win/bdieintsi.exe/ NIVZ101290009000020002\#ARBOL. 
(2013b), "Encuesta Industrial Anual. Clasificación Mexicana de Actividades y Productos (CMAP), 205 clases de actividad económica" [en línea] http://dgcnesyp.inegi.org.mx/cgi-win/ bdieintsi.exe/NIVZ1012900110\#ARBOL.

(2010), "El sector automotriz en México 2010", Serie Estadísticas Sectoriales, $\mathrm{N}^{\circ} 25$, México, D.F.

MacKinnon, D. (2012), "Beyond strategic coupling: reassessing the firm-region nexus in global production networks", Journal of Economic Geography, vol. 12, № 1, Oxford, Oxford University Press, enero.

Ocampo, J. (2005), "La búsqueda de la eficiencia dinámica: Dinámica estructural y crecimiento económico en los países en desarrollo", Más allá de las reformas: Dinámica estructural y vulnerabilidad macroeconómica, J. Ocampo (ed.), Bogotá, D.C., CEPAL/Alfaomega.

Phelps, N.A. (2008), "Cluster or capture? Manufacturing foreign direct investment, external economies and agglomeration", Regional Studies, vol. 42, $\mathrm{N}^{\circ}$ 4, Taylor and Francis, mayo.

Pinto, A. (1970), "Naturaleza e implicaciones de la "heterogeneidad estructural' de la América Latina", El Trimestre Económico, vol. 37, N 145, México, D.F., Fondo de Cultura Económica, enero-marzo.

(1965), "Concentración del progreso técnico y de sus frutos en el desarrollo de América Latina", El Trimestre Económico, vol. 32, N 125, México, D.F., Fondo de Cultura Económica, enero-marzo.

Puyana, A. y J. Romero (2006), "Hacia una evaluación de los efectos multiplicadores de la actividad maquiladora", Estudios
Sociológicos, vol. 24, $\mathrm{N}^{\circ}$ 1, México, D.F., El Colegio de México, enero-abril.

Unger, K. (2001), "La organización industrial, productividad y estrategias empresariales en México", Economía Mexicana. Nueva Época, vol. 10, $\mathrm{N}^{\circ}$ 1, México, D.F., Centro de Investigación y Docencia Económicas, enero-junio.

Vázquez, R. (2013), "Heterogeneidad estructural y sus determinantes en la manufactura mexicana, 1994-2008", Revista de la CEPAL, $\mathrm{N}^{\circ} 109$ (LC/G.2556-P), Santiago de Chile, abril.

(2012), "Heterogeneidad y cambio estructural en el sector manufacturero mexicano", Globalización y dinamismo manufacturero. México y otros países emergentes, M.L. González y B. Olmedo (coords.), México, D.F., Instituto de Investigaciones Económicas, Universidad Nacional Autónoma de México.

Yamashita, N. (2008), "The impact of production fragmentation on skill upgrading: new evidence from Japanese manufacturing", Working Papers in Trade and Development, $\mathrm{N}^{\circ} 2008 / 06$, Canberra, The Australian National University.

Yeats, A. (2001), "Just how big is global production sharing?", Fragmentation: New Production Patterns in the World Economy, S. Arndt y H. Kierzkowski (eds.), Oxford, Oxford University Press.

Yeung, H. (2009), "Transnational corporations, global production networks and urban and regional development: a geographer's perspective on multinational enterprises and the global economy", Growth and Change, vol. 40, $\mathrm{N}^{\circ} 2$, Wiley, junio. 